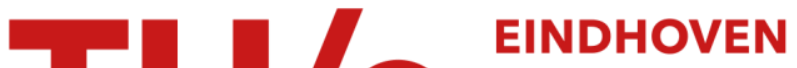 UNIVERSITY OF TECHNOLOGY
}

\section{$47.4 \mathrm{~Gb} / \mathrm{s}$ tranmission over $100 \mathrm{~m}$ graded-index plastic optical fiber based on rate-adaptive discrete multitone modulation}

\section{Citation for published version (APA):}

Yang, H., Lee, S. C. J., Tangdiongga, E., Okonkwo, C. M., Boom, van den, H. P. A., Breyer, F., Randel, S., \& Koonen, A. M. J. (2010). $47.4 \mathrm{~Gb} / \mathrm{s}$ tranmission over $100 \mathrm{~m}$ graded-index plastic optical fiber based on rateadaptive discrete multitone modulation. Journal of Lightwave Technology, 28(4), 352-359.

https://doi.org/10.1109/JLT.2009.2034393

DOI:

10.1109/JLT.2009.2034393

Document status and date:

Published: 01/01/2010

\section{Document Version:}

Publisher's PDF, also known as Version of Record (includes final page, issue and volume numbers)

\section{Please check the document version of this publication:}

- A submitted manuscript is the version of the article upon submission and before peer-review. There can be important differences between the submitted version and the official published version of record. People interested in the research are advised to contact the author for the final version of the publication, or visit the $\mathrm{DOI}$ to the publisher's website.

- The final author version and the galley proof are versions of the publication after peer review.

- The final published version features the final layout of the paper including the volume, issue and page numbers.

Link to publication

\section{General rights}

Copyright and moral rights for the publications made accessible in the public portal are retained by the authors and/or other copyright owners and it is a condition of accessing publications that users recognise and abide by the legal requirements associated with these rights.

- Users may download and print one copy of any publication from the public portal for the purpose of private study or research.

- You may not further distribute the material or use it for any profit-making activity or commercial gain

- You may freely distribute the URL identifying the publication in the public portal.

If the publication is distributed under the terms of Article 25fa of the Dutch Copyright Act, indicated by the "Taverne" license above, please follow below link for the End User Agreement:

www.tue.nl/taverne

Take down policy

If you believe that this document breaches copyright please contact us at:

openaccess@tue.nl

providing details and we will investigate your claim. 


\title{
47.4 Gb/s Transmission Over 100 m Graded-Index Plastic Optical Fiber Based on Rate-Adaptive Discrete Multitone Modulation
}

\author{
Hejie Yang, Student Member, IEEE, S. C. Jeffrey Lee, Student Member, IEEE, Eduward Tangdiongga, \\ Chigo Okonkwo, Student Member, IEEE, Henrie P. A. van den Boom, Florian Breyer, Student Member, IEEE, \\ Sebastian Randel, Member, IEEE, and A. M. J. Koonen, Fellow, IEEE
}

\begin{abstract}
We experimentally demonstrate a bit-rate of 47.4 Gb/s over $100 \mathrm{~m}$ of perfluorinated multimode graded-index plastic optical fiber (GI-POF) by exploiting discrete multitone (DMT) modulation with rate-adaptive bit-loading. The maximum achieved aggregate bit rate is $51.8 \mathrm{~Gb} / \mathrm{s}$ including DMT transmission overhead (cyclic prefix and preambles) and the standard of $7 \%$ of forward-error-correction (FEC) overhead. This is achieved over an intensity-modulated direct-detection (IM-DD) link using a directly-modulated DFB laser (1300-nm) and a multimode fiber-coupled photodetector with a large diameter of $25-\mu \mathrm{m}$. The bandwidth requirement is only $12 \mathrm{GHz}$ due to the use of spectral-efficient modulation formats of up to 64-QAM.
\end{abstract}

Index Terms-Frequency division multiplexing, Optical fiber communication, quadrature amplitude modulation, signal processing, subcarrier multiplexing.

\section{INTRODUCTION}

$\mathbf{I}$ $\mathrm{N}$ recent years, there has been increasing use of commercial perfluorinated graded-index plastic optical fiber (GI-POF) with core diameters of 50-62.5 $\mu \mathrm{m}$ for $10 \mathrm{~Gb} / \mathrm{s}$ short-reach applications such as low-cost interconnects in datacenters, local area networks (LAN), and supercomputers. For such applications, multimode fibers (MMF) such as the GI-POF are preferred above single-mode fiber due to their large core diameter and numerical aperture. Due to the large alignment tolerances in transceiver components and fiber splices, MMF is attractive for in-building networks as its installation is easy and at low cost. In addition, when compared to silica MMF, GI-POF offers further advantages such as smaller bending radius $(5 \mathrm{~mm})$, better tolerance to tensile load and stress, and simpler connectorization.

Recent developments in the standardization of higher-speed networking standards like 40 and 100 Gigabit Ethernet also in-

\footnotetext{
Manuscript received May 31, 2009; revised August 19, 2009. First published November 03, 2009; current version published January 29, 2010. This work was supported in part by the Dutch national program IOP-GenCom IGC0507 on Future Home Networks and the EU program FP7 ICT-212352 ALPHA.

H. Yang, S. C. J. Lee, E. Tangdiongga, C. Okonkwo, H. P. A. van den Boom, and A. M. J. Koonen are with the COBRA Research Institute, Technical University of Eindhoven, 5600MB Eindhoven, the Netherlands (e-mail: h.yang1; s.c.j.lee; e.tangdiongga; c.m.okonkwo; h.p.a.v.d.boom; a.m.j.koonen@tue.nl).

F. Breyer is with the Lehrstuhl für Nachrichtentechnik, Technische Universität München, Munich D-80333, Germany. (e-mail: florian.breyer@tum.de).

S. Randel is with Siemens AG, Corporate Technology, Information and Communication, Munich D-81739, Germany (e-mail: sebastian.randel@siemens. com).
}

Digital Object Identifier 10.1109/JLT.2009.2034393 clude MMF as physical medium [1], thereby paving the way for low-cost optical networking at speeds beyond $10 \mathrm{~Gb} / \mathrm{s}$. Although current proposals consider parallel transmission of multiple $10 \mathrm{~Gb} / \mathrm{s}$ MMF links with multiple fibers or multiple wavelengths to achieve higher speeds, serial transmission using only one MMF is attractive because issues such as skew between parallel fibers or multiple wavelengths, inter-channel crosstalk, and reduced reliability due to higher complexity can be avoided. Several research groups have demonstrated $40 \mathrm{~Gb} / \mathrm{s}$ serial transmission over GI-POF [2]-[4]. However, these results were obtained with expensive large-bandwidth $(>25 \mathrm{GHz})$ single-mode fiber components such as external Mach-Zehnder modulators and small-area high-bandwidth detectors [3], [4], as well as optical fiber amplifiers [2], which are neither practical nor suitable for low-cost applications.

In this paper, we demonstrate that by exploiting discrete multitone modulation (DMT) with up to 64-state quadrature amplitude modulation (64-QAM), off-the-shelf and low-cost components such as standard 1300-nm directly-modulated distributed feedback (DFB) laser diode (with 12-GHz bandwidth) and an MMF-coupled 25- $\mu \mathrm{m}$ large diameter photodetector can be used to achieve more than $47 \mathrm{~Gb} / \mathrm{s}$ serial transmission over $100 \mathrm{~m}$ of 50- $\mu \mathrm{m}$ core diameter GI-POF. This demonstrates the potential of DMT for enabling highly spectral efficient transmission at high bit-rates over MMF, while overcoming the fiber's modal dispersion and allowing the use of conventional narrow-bandwidth transceivers [5]-[10]. It is therefore a promising solution for low-cost, robust, and high-capacity MMF and GI-POF LAN links operating at data rates of $40 \mathrm{~Gb} / \mathrm{s}$ and beyond.

The paper is organized as follows: after the introduction in Section I, the principle of DMT and bit-loading is briefly explained in Section II. Moreover, rate-adaptive bit-loading is proposed for maximizing the achievable transmission rate over GI-POF. Section III presents the experimental setup in detail and discusses experimental investigations regarding the influence of laser non-linearity and the number of DMT subcarriers on system performance. In Section IV, detailed experimental results of the transmission performance of the record $47.4 \mathrm{~Gb} / \mathrm{s}$ over $100 \mathrm{~m}$ GI-POF are presented. Finally, the paper is concluded in Section V.

\section{DMT AND BIT-LOADING}

Derived from the more general orthogonal frequency division multiplexing (OFDM) [6], DMT is a baseband version [7], [12] 
that is widely applied in large scale to digital subscriber copper lines (ADSL, VDSL, etc.) and power-line communication systems, proving that low-cost implementation in combination with existing MMF transceivers can be possible [8].

An important feature of DMT is the possibility to allocate the number of bits per subcarrier according to its corresponding signal-to-noise ratio (SNR), typically known as bit-loading. Bit-loading can be divided into two categories: rate-adaptive and margin-adaptive. Rate-adaptive algorithms maximize the bit rate for a fixed bit-error ratio (BER) and given power constraint, while margin-adaptive algorithms minimize the BER for a given bit rate. In this paper, rate-adaptive bit-loading will be considered in order to maximize the transmission rate over GI-POF [9], [11].

The rate-adaptive bit-loading algorithm is a reformulation of the Shannon capacity formula [12] and can be expressed as a problem of maximizing the total achievable normalized bit-rate $b$, which is the sum of the normalized bit-rates per subcarrier used for DMT transmission:

$$
\begin{aligned}
\max _{\mathrm{E}_{n}}(b) & =\max _{\mathrm{E}_{n}}\left(\sum_{n=1}^{N-1} \log _{2}\left(1+\frac{\mathrm{SNR}_{n}}{\Gamma}\right)\right) \\
& =\max _{\mathrm{E}_{n}}\left(\sum_{n=1}^{N-1} \log _{2}\left(1+\frac{E_{n} \cdot g_{n}}{\Gamma}\right)\right)
\end{aligned}
$$

where $\mathrm{SNR}_{n}=E_{n} \cdot g_{n}$ is the SNR per subcarrier, $g_{n}$ represents the subcarrier SNR when unit energy is applied, $\Gamma$ is the difference (gap) between the SNR needed to achieve maximum (Shannon) capacity and the SNR to achieve this capacity at a given bit error probability, and $E_{n}$ is the allocated energy per subcarrier, subject to an energy constraint given by:

$$
\sum_{n=1}^{N-1} E_{n}=E_{\mathrm{tot}} .
$$

$E_{\text {tot }}$ is the fixed total available energy for transmission. The problem is now to find the optimum number of bits per subcarrier, and the corresponding energy distribution per subcarrier $E_{n}$, in order to maximize the bit-rate.

The solution to this bit-rate maximization problem, based on the use of Lagrange multipliers, is commonly known as waterfilling. In [13], Chow proposed that the water-filling solution can be computed numerically and the finite bit-loading algorithm easily adapted for practical use. The algorithm, based on (1), initially discards the subcarriers that are least energy-efficient from information transmission, and redistributes the energy to more efficient subcarriers in order to support higher data rates. The non-integer number of allocated bits per subcarrier are then rounded to the nearest integer and the corresponding energy is dynamically adapted to support the newly-allocated number of bits at the same performance.

From (1), notice that $E_{n}$ of some of the subcarriers can be set to zero in order to achieve the maximum normalized bit-rate $b$. Therefore, the optimal solution is not always to use all $N-1$ available subcarriers to transmit information. Chow's algorithm has been shown to achieve near-optimum performance [12], [13] and will be used to compute rate-adaptive bit-loading for the following DMT over GI-POF measurements.

\section{RESULTS AND DiscUSSION}

\section{A. Experimental Setup}

In order to realize more than $40 \mathrm{~Gb} / \mathrm{s}$ transmission over GI-POF, different system parameters have to be investigated and optimized. For this, the experimental setup depicted in Fig. 1 is used. Using a Tektronix AWG7122B arbitrary waveform generator (AWG) with a bandwidth of $10 \mathrm{GHz}$, a DFB laser is directly modulated (through an electrical variable attenuator and amplifier) at a sampling speed of 24 GSamples/s. To achieve this sampling speed, the two outputs of the AWG, both at 12 GSamples/s, are interleaved. The DFB laser, with a wavelength of $1302 \mathrm{~nm}$, is specified for up to $10 \mathrm{~Gb} / \mathrm{s}$ on-off keying transmission and has an electrical small-signal modulation bandwidth of approximately $12 \mathrm{GHz}$. The resulting intensity-modulated optical signal is then either transmitted over 100 meters of $50-\mu \mathrm{m}$ core perfluorinated GI-POF, or directly coupled to the multimode variable optical attenuator in the back-to-back measurement case. After the multimode attenuator, the received optical signal is detected by a multimode-fiber-coupled photo-detector (PD) with a detection diameter of $25-\mu \mathrm{m}$ and an integrated coupling lens. The resulting received electrical signal is then amplified and captured using a 16-GHz real-time Tektronix DPO72004 digital storage oscilloscope (DSO) running at a sampling rate of 50 GSamples/s for demodulation and evaluation. The clocks of the AWG and DSO are not synchronized, so that clock/phase recovery has to be performed by the DMT demodulator as well.

For the DMT transmission, a computer is used to emulate the digital DMT modulator and demodulator, as shown in Fig. 1. This also includes offline clock/phase recovery, evaluation of transmission performance parameters such as BER and SNR per subcarrier, and the computation of the bit-loading algorithm.

\section{B. Influence of Laser Non-Linearity}

The parameters of the DMT signal used for the laser non-linearity measurements are given in Table I. It should be noted that the DMT signal is clipped in the electrical digital domain before digital-to-analog (D/A) conversion due to reasons of dynamic range [14], [15]. As a result of this digital clipping, the analogue current $\mathrm{I}_{\mathrm{pp}}$ after D/A conversion for driving the DFB laser will have a maximum peak-to-average power ratio defined by the clipping factor:

$$
\mu_{\mathrm{dB}}=20 \cdot \log _{10}\left(\frac{I_{\mathrm{pp}}}{I_{\mathrm{rms}}}\right),
$$

where $\mathrm{I}_{\text {rms }}$ denotes the root-mean-square DMT signal current. In [14] and [15], the optimum clipping factor for DMT in an IM-DD channel was already investigated and found to be approximately $10 \mathrm{~dB}$. Therefore, this value will be used for all measurements presented in this paper.

Initially, all subcarriers are loaded with 3 information bits each, corresponding to a modulation format of 8-QAM. From the received and demodulated DMT signal, the SNR per subcarrier is estimated and used to compute bit-loading in order to maximize transmission performance. Due to the use of Chow's rate-adaptive bit-loading in this experiment, system 


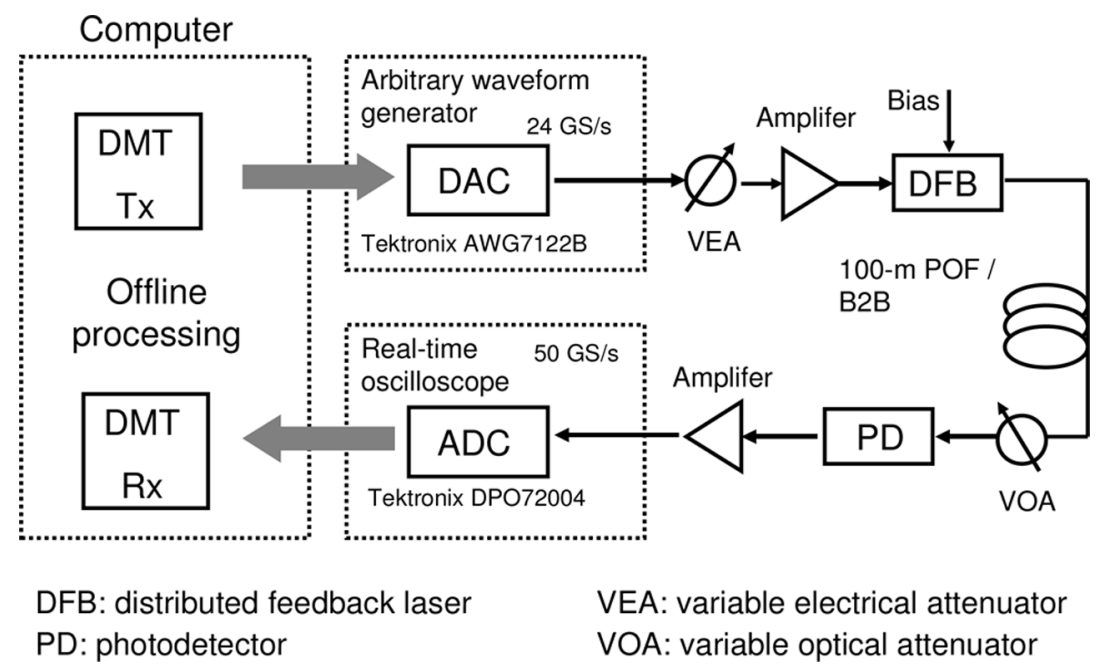

Fig. 1. Measurement setup for DMT over GI-POF transmission.

TABLE I

DMT SIGNAL PARAMETERS

\begin{tabular}{ll}
\hline \hline Nr. of subcarriers: & 256 (254 used, first and last not used at all $)$ \\
Cyclic prefix: & 8 out of 520 points \\
Preambles: & 4 preambles per 200 DMT frames \\
Digital clipping: & Clipping factor $\mu=10 \mathrm{~dB}$ \\
\hline \hline
\end{tabular}

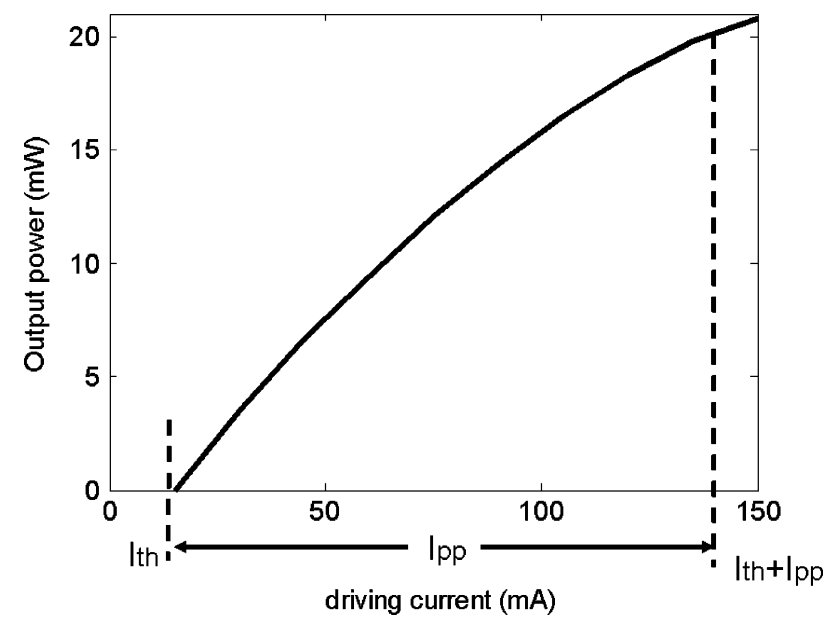

Fig. 2. Optical output power versus DFB driving currents used in the experiments. $\mathrm{I}_{\mathrm{th}}$ : threshold current; $\mathrm{I}_{\mathrm{pp}}$ : peak-to-peak driving current.

performance is characterized by the maximum achievable transmission rate at a fixed BER of $10^{-3}$.

Fig. 2 shows schematically how the peak-to-peak driving current $I_{p p}$ is varied for the DFB laser. The laser is always fully modulated starting from its threshold current $\mathrm{I}_{\mathrm{th}}$. The laser bias current, which is equal to $\mathrm{I}_{\mathrm{pp}} / 2+\mathrm{I}_{\mathrm{th}}$, is adjusted according to $\mathrm{I}_{\mathrm{pp}}$ in order to ensure full modulation of the DFB laser. The average received optical power is always fixed to the same value with the variable optical attenuator when $\mathrm{I}_{\mathrm{pp}}$ is increased. By this method, the influence of thermal noise (resulting mainly from the electrical amplifier at the receiver) is kept constant when $I_{p p}$ is varied.

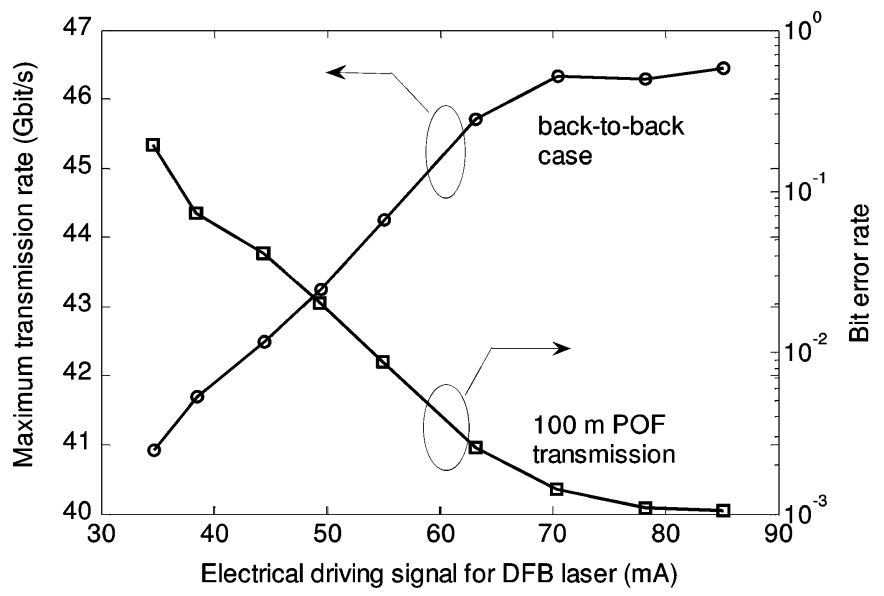

Fig. 3. left axis: Transmission rate versus peak-to-peak driving current with rate-adaptive bit-loading; right axis: BER versus driving current with fixed bitloading parameters.

Fig. 3 presents the effect of peak-to-peak electrical driving current $\mathrm{I}_{\mathrm{pp}}$ on the system performance in both back-to-back and GI-POF transmission system. In this measurement we set the laser bias level to be fixed at $60 \mathrm{~mA}$ and thus the received optical power is fixed at $+4 \mathrm{dBm}$. In the left vertical axis we show the maximum transmission rate for different peak-to-peak driving current levels up to $85 \mathrm{~mA}$ with adaptive bit loading. The transmission rate is saturated for peak-to-peak driving currents of $70 \mathrm{~mA}$ and above, at which the maximum rate is achieved. On the right vertical axis, the bit error rate (BER) is plotted versus different peak-to-peak driving currents for transmission. We keep the fixed laser bias level and received optical power, as well as fixed bit loading parameters in transmission measurement. A similar floor in BER is observed for comparison with back-to-back case. This saturation in system performance might be due to the DMT electrical clipping noise and laser non-linearity.

From the back-to-back measurement results of Fig. 4, we see a similar performance as in Fig. 3. For a fixed driving current, the system performance increases for larger received op- 


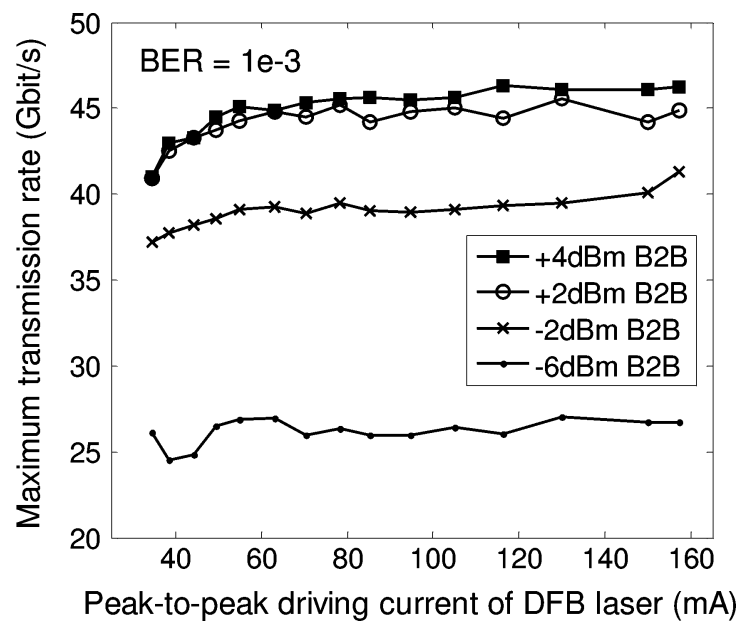

Fig. 4. Maximum achievable transmission rate @ BER $=10^{-3}$ as a function of peak-to-peak laser drive currents for different received optical powers.

tical power, which is apparent due to less influence of receiver (thermal) noise. However, at $+4 \mathrm{dBm}$ received optical power, performance seems to be limited and the achievable transmission rate seems to saturate at its maximum value. Possible reasons for this limit are saturation effects of the photodetector at high received optical powers and the electrical DMT clipping noise noise resulting from clipping the electrical DMT signal in the digital domain before D/A conversion.

The results from transmission experiments over $100 \mathrm{~m}$ GI-POF is investigated and shown in Fig. 5. The corresponding back-to-back curves in Fig. 4 are included for reference. The performance degrades for larger peak-to-peak laser drive currents in the case of transmission over $100 \mathrm{~m}$ GI-POF. The reduced transmission rate can be attributed to the change in the shape of the frequency response at higher laser currents, as shown in Fig. 6. At higher laser currents, the frequency response reduces the available bandwidth, hence detrimental to the achievable rate. Note that in Fig. 5, at higher launch powers, the maximum transmission rate decreases. This can be attributed to differential modal attenuation (DMA) [16], [17], which is the effect that higher order modes propagating through the GI-POF experience higher attenuation than the fundamental modes. At low launch power, almost only the fundamental modes can be detected after $100 \mathrm{~m}$ GI-POF due to the DMA effect. However, for very high optical launch powers, the higher order modes are not attenuated enough at a distance of $100 \mathrm{~m}$ and are therefore also detected at the end of the GI-POF. This difference in mode attenuation profile leads to constructive/destructive modal interference, and affects in this case the GI-POF bandwidth in a negative way (as can be observed in Fig. 6).

Additionally, the limitation due to detector saturation in Fig. 5 can be noticed again in the curves with $100 \mathrm{~m}$ GI-POF as no significant improvement in transmission rate is observed between $+2 \mathrm{dBm}$ and $+4 \mathrm{dBm}$.

\section{Influence of Number of Subcarriers}

In addition to the impact of laser non-linearity, the influence of the number of subcarriers used for DMT transmission is also

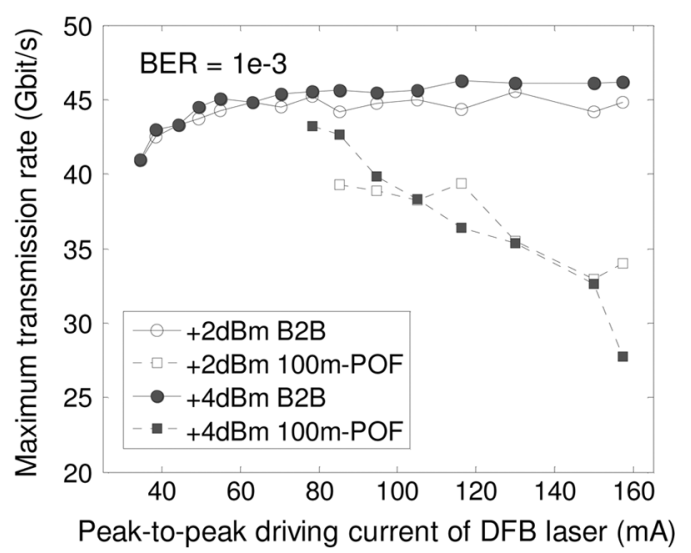

Fig. 5. Maximum achievable transmission rate @ $B E R=10^{-3}$ versus peak-to-peak laser drive currents for different received optical powers.

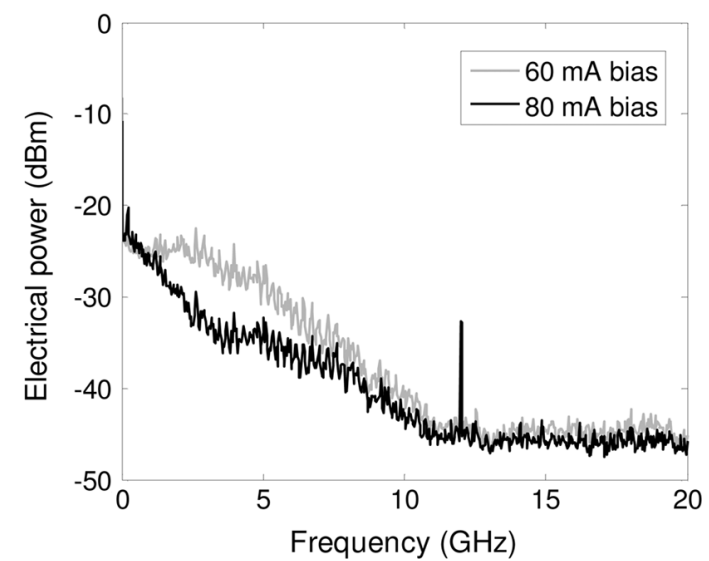

Fig. 6. Measured frequency response of $100 \mathrm{~m} \mathrm{GI} \mathrm{POF}$ at 60 and $80 \mathrm{~mA}$ laser bias current.

investigated experimentally. The same DMT parameters as in Section III.B are used, except that the total number of subcarriers is now varied from 128 to 512 . The received optical power is fixed at $+4 \mathrm{dBm}$. Again, with rate-adaptive bit-loading, the power and bit-allocation per subcarrier is adapted to the transmission channel, thereby maximizing the transmission rate to a fixed BER of $10^{-3}$.

Fig. 7 shows the experimental results for the back-to-back case. As observed in Fig. 7, the system performance improves when the number of DMT subcarriers is increased. To further investigate this, the total number of DMT subcarriers is varied over a larger range for the same received optical power of $+4 \mathrm{dBm}$. The peak-to-peak driving current $\mathrm{I}_{\mathrm{pp}}$ of the DFB laser is fixed to $85 \mathrm{~mA}$. The measurement results are plotted in Fig. 8, for the case of back-to-back and $100 \mathrm{~m}$ of GI-POF.

As shown in Fig. 8, the transmission rate improves with the increase of the DMT subcarrier counts. This is true for back-toback and for $100 \mathrm{~m}$ of GI-POF. The conclusion is that with a larger number of subcarriers, the frequency response of the transmission channel can be more finely divided into more subchannels, making the channel response of each subcarrier flatter. Consequently, every subcarrier experiences a better channel response and therefore overall performance increases. 


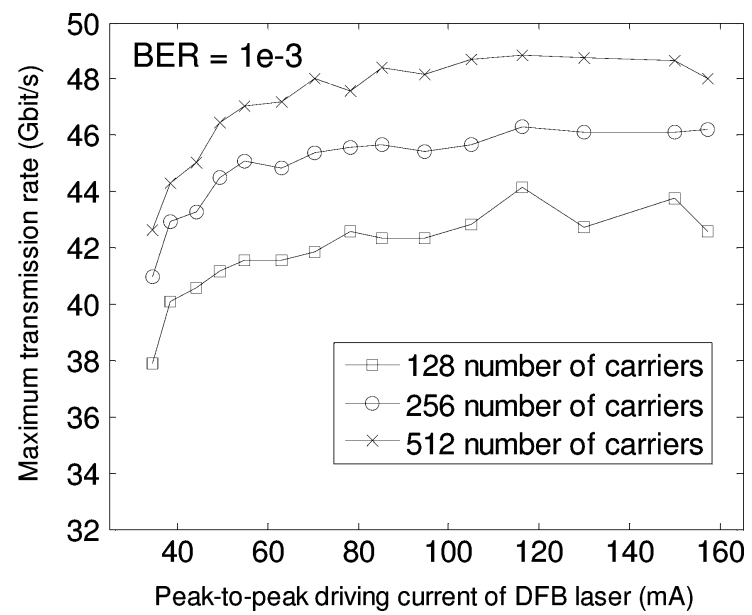

Fig. 7. Maximum achievable transmission rate @ BER $=10^{-3}$ versus peak-to-peak laser drive currents for different number of subcarriers.

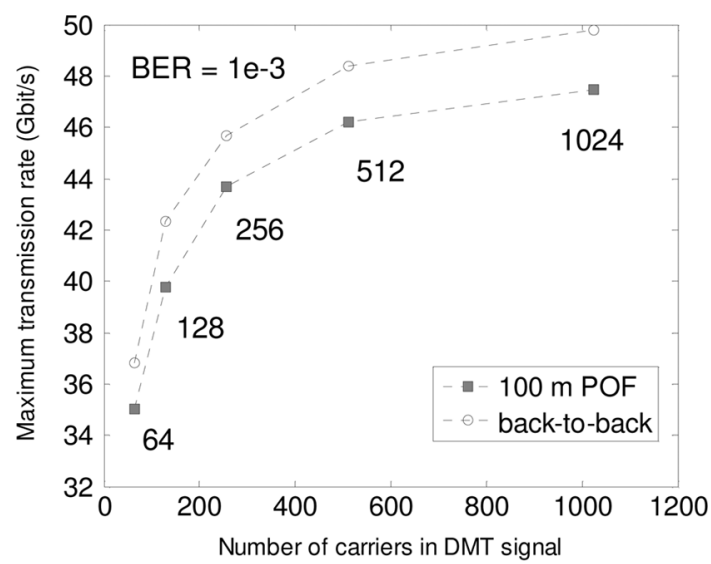

Fig. 8. Maximum achievable transmission rate @ $\mathrm{BER}=10^{-3}$ for different number of subcarriers. Received optical power is fixed at $+4 \mathrm{dBm}$.

The performance gap between $100 \mathrm{~m}$ GI-POF and the back-to-back case is due to the extra bandwidth limitation of the GI-POF. The attenuation of GI-POF is not significant in Fig. 8 because the received optical power and peak-to-peak laser driving current are both fixed to the same values for each measurement point. It can also be noted that the number of subcarriers cannot be increased infinitely in order to have better performance, as flatter curves can be seen after 512 subcarriers.

\section{Influence of Clipping Levels}

Fig. 9 presents the BER measurement as a function of received optical powers for different values of the DMT electrical clipping levels $\mu_{\mathrm{dB}}$ as defined in (3). The parameters for DMT bit-loading are fixed as well as the bias and driving current of the laser. The optimum clipping factor is found to be around $10 \mathrm{~dB}$. For smaller values of $\mu_{\mathrm{dB}}$, the performance is worse due to the high peak-to-average power ratio (dynamic range) of the DMT signal. Significantly more clipping noise is introduced when $\mu_{\mathrm{dB}}$ is increased beyond $10 \mathrm{~dB}$. Therefore, system performance deteriorates. However, clipping is essential to optimize and limit the peak power of DMT signals because constructive

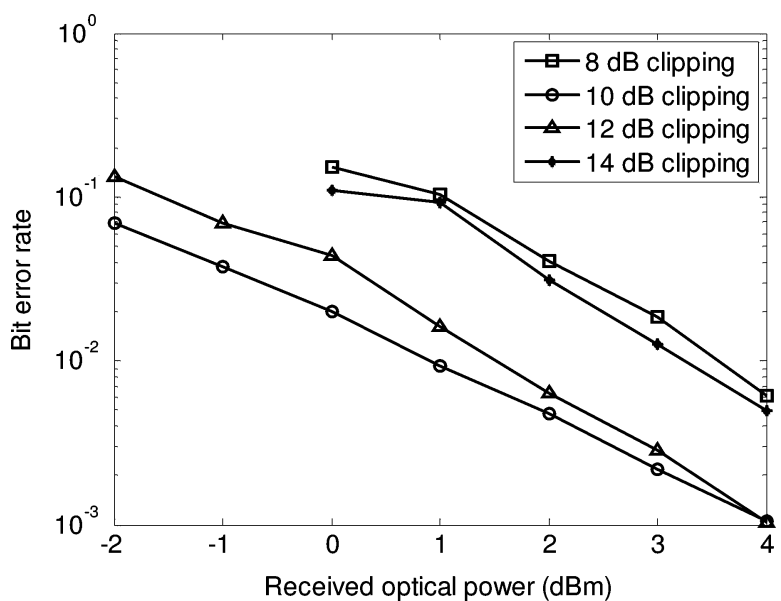

Fig. 9. BER values versus received optical powers for different levels of DMT electrical clipping.

phase addition of a large number of subcarriers can cause very high signal peaks [15].

\section{E. Influence of Modal Noise}

Up to an $\mathrm{I}_{\mathrm{pp}}$ of $85 \mathrm{~mA}$, modal noise is not observed. This is because light of a single-mode DFB laser with single mode pigtail (small launching area) is launched into the GI-POF, thereby exciting only lower order modes. Due to mode coupling in the GI-POF, higher order modes can still exist but most are suppressed by DMA. Additionally, a commercial photodetector with integrated coupling lens is used to couple most of the light from the end of the GI-POF into the detector. (The effective detector diameter is $21 \mu \mathrm{m}$.) For $\mathrm{I}_{\mathrm{pp}}$ larger than $85 \mathrm{~mA}$, beginning signs of modal noise can be observed, because of high laser launch power. Due to such high launching power (up to $+10 \mathrm{dBm}$ ), DMA in the GI-POF is not large enough to suppress the higher order modes resulting from mode coupling in the GI-POF. Therefore, higher-order modes are present at the GI-POF end-face and some are not detected by the photodetector, leading to beginning signs of modal noise. As the results are obtained at Ipp of $85 \mathrm{~mA}$, these results do not suffer from modal noise.

In conclusion, a record net transmission bit-rate of $47.4 \mathrm{~Gb} / \mathrm{s}$ is achieved over $100 \mathrm{~m}$ of GI-POF using DMT based on a total of 1024 subcarriers and the clipping level of $10 \mathrm{~dB}$. To the authors' knowledge, this is the highest bit-rate ever reported for GI-POF transmission.

\section{IV. $47.4 \mathrm{~GB} / \mathrm{S}$ TRANSMISSION OVER $100 \mathrm{M}$ GI-POF}

In this section, details of the transmission performance of DMT for a net bit-rate of $47.4 \mathrm{~Gb} / \mathrm{s}$ over $100 \mathrm{~m}$ GI-POF are also presented. This transmission result corresponds to the $100-\mathrm{m}$ POF marker point at 1024 DMT subcarriers in Fig. 8. In the experiment, 1024 subcarriers are used for the DMT transmission, ranging from a frequency of 0 to $12 \mathrm{GHz}$. Fig. 10(a) shows the measured SNR per subcarrier in the initialization stage, prior to applying Chow's rate-adaptive bit-loading algorithm, after transmission over $100 \mathrm{~m}$ GI-POF. The channel response is clearly adapted by the large amount of subcarriers in detail. The bit and power allocation per subcarrier, after applying 

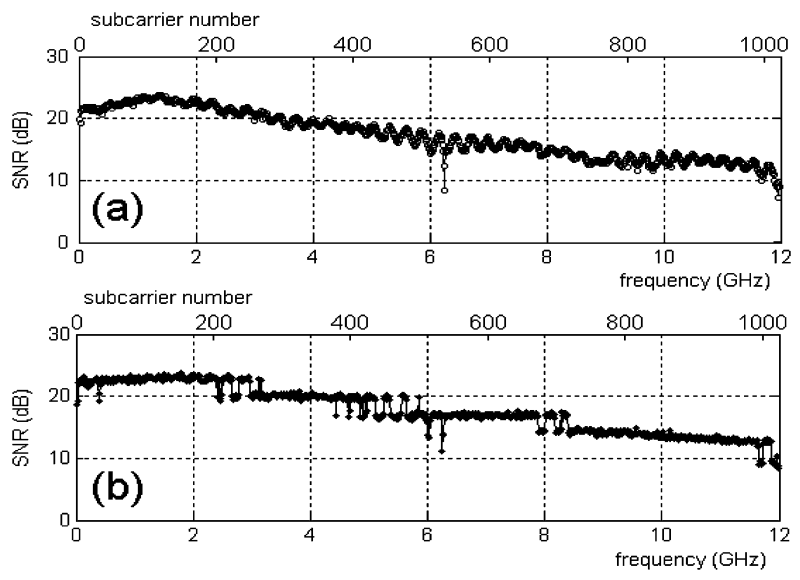

Fig. 10. Measured SNR per subcarrier for DMT transmission over $100 \mathrm{~m} \mathrm{GI}$ POF, (a) before (b) after rate-adaptive bit-loading.

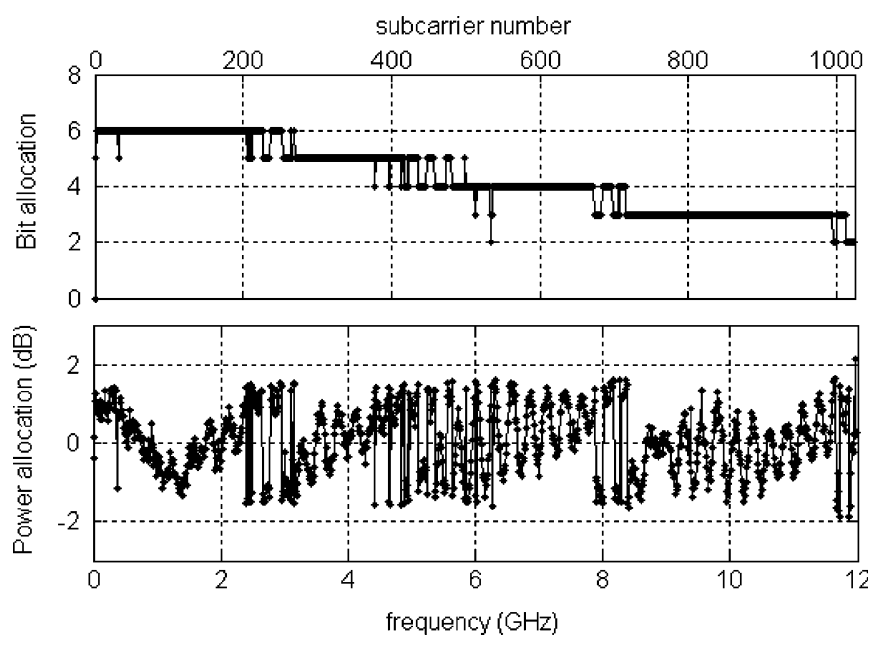

Fig. 11. Rate-adaptive bit-loading parameters for DMT transmission over $100 \mathrm{~m}$ GI-POF using a total of 1024 subcarriers.

rate-adaptive bit-loading, is depicted in Fig. 11. For subcarriers with the highest SNR, 6 bits are allocated for DMT transmission, which is realized by 64-QAM. The number of allocated bits per subcarrier decreases to 2 , for those subcarriers with the lowest SNR. This is equivalent to a modulation format of 4-QAM. By allocating a different amount of power to each individual subcarrier, the SNR per subcarrier can be fine-tuned to a fixed value, which is just enough to achieve a BER of $10^{-3}$ for the specific modulation format. The resulting SNR per subcarrier after rate-adaptive bit-loading is shown in Fig. 10(b). Note that the SNR per subcarrier is stair-case-shaped, as a result of the bit-loading algorithm. A total of 4421 bits are allocated per DMT frame. Fig. 12 presents the measured BER values as a function of the subcarrier index for the received $47.4 \mathrm{~Gb} / \mathrm{s}$ DMT signal. In the DMT transmission scheme, the signal is not demodulated per subcarrier but as an entire frame. This provides the benefit that even if some subcarriers have BER values larger than $10^{-3}$, the signal quality is still good enough to achieve a total average BER of $10^{-3}$. This value is under the FEC limit for error-free operation.

In Fig. 13, we present the electrical spectra of the signal as observed before and after 100-m transmission. The available

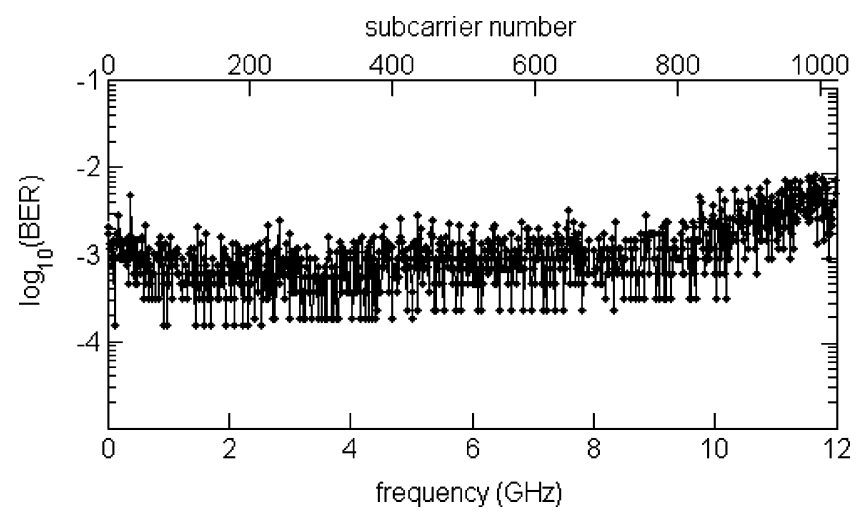

Fig. 12. BER performance per DMT subcarrier after transmission over $100 \mathrm{~m}$ GI-POF.

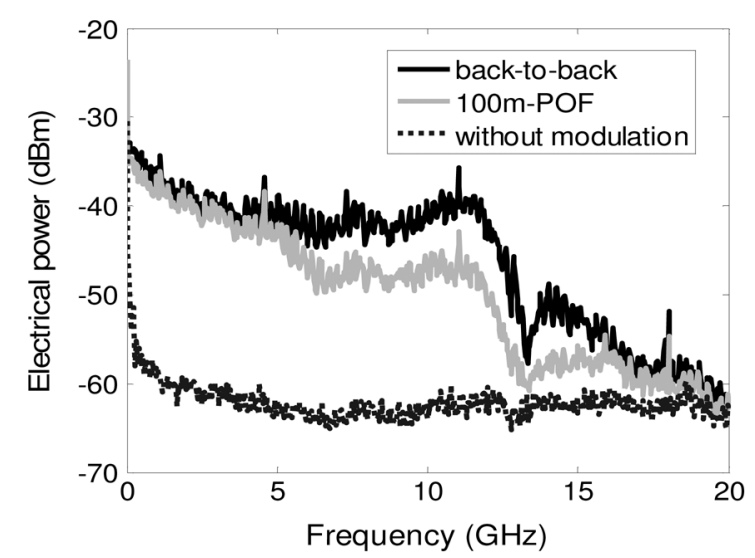

Fig. 13. Received signal spectrum after 100-m POF, compared to the back-toback case and the case without modulation.

bandwidth for data transmission is seen as less than $13 \mathrm{GHz}$, taking into account the bandwidth of the AWG and the DFB laser. However, the DMT scheme and the bit-loading algorithm allow us to successfully transmit $47.4 \mathrm{~Gb} / \mathrm{s}$ data through such narrow bandwidths. The gray curve is the spectrum without data modulation, which indicates the noise floor of the system.

In Fig. 14, the superimposed constellation diagrams of the first 20 subcarriers with 64-QAM and the last 10 subcarriers with 4-QAM are shown. These constellations are respectively the largest and smallest of the DMT transmission system over $100 \mathrm{~m}$ GI-POF. The clearly distinguishable constellation points indicate that the received signal quality is good and that the one-tap channel equalizers in the DMT demodulator are working as expected.

\section{CONCLUSION}

By characterizing the influence of laser non-linearity and the number of subcarriers on DMT transmission performance over GI-POF using experimental results, optimum parameters for best system performance could be determined. Compared to the results presented in [9], the maximum achievable transmission rate with the optimum parameters is improved to a record of $47.4 \mathrm{~Gb} / \mathrm{s}$ transmission over $100 \mathrm{~m}$ GI-POF. This is achieved by exploiting DMT transmission with Chow's rate-adaptive bit-loading scheme. To the authors' knowledge, 

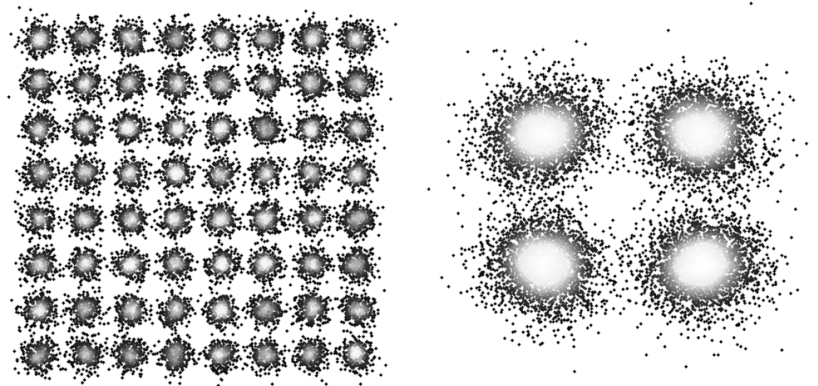

Fig. 14. Plots of the highest (64-QAM) and lowest (4-QAM) constellations used in $47.4 \mathrm{~Gb} / \mathrm{s}$ DMT transmission over $100 \mathrm{~m}$ GI-POF.

this is the highest bit-rate ever reported for GI-POF transmission and proves that DMT is indeed a promising solution for enabling high-capacity transmission over standard low-cost and easy-to-use MMF and GI-POF links.

Although current $40 \mathrm{GbE}$ and $100 \mathrm{GbE}$ proposals regard only parallel transmission of multiple $10 \mathrm{~Gb} / \mathrm{s}$ links in order to achieve higher speeds, the proposed idea of serial transmission at similar bandwidth requirements by use of DMT can result in even lower-cost systems. While one might argue that digital signal processing will increase power consumption, significant power savings resulting from using less transceivers and the inherently reduced complexity can offer a good trade-off to make DMT a viable solution for high-speed, low-power, and low-cost serial optical networking operating at bit-rates of 40 $\mathrm{Gb} / \mathrm{s}$ and beyond. Moreover, DMT has proven to be a robust technique to adaptively compensate the modal dispersion of multimode GI-POF links, and in this way counteracting the dispersion variations which may occur due to changing fiber launching and bending conditions.

\section{REFERENCES}

[1] IEEE P802.3ba $40 \mathrm{~Gb} / \mathrm{s}$ and $100 \mathrm{~Gb} / \mathrm{s}$ Ethernet Task Force, [Online]. Available: http://www.ieee802.org/3/ba/, [Online]. Available:

[2] J. Yu, " $42.8 \mathrm{~Gb} / \mathrm{s}$ chirp-managed signal transmission over $100 \mathrm{~m}$ graded-index plastic optical fiber," in Proc. OFC 2008, Paper PDP-28.

[3] S. Schöllmann et al., "First experimental transmission over $50 \mathrm{~m}$ GI-POF at $40 \mathrm{~Gb} / \mathrm{s}$ for variable launching offsets," in Proc. ECOC 2007, Paper PDP 3.7.

[4] A. Polley, "40 Gbps links using plastic optical fiber," in Proc. OFC 2007, Paper OMR5.

[5] S. C. J. Lee, F. Breyer, S. Randel, D. Cárdenas, H. P. A. van den Boom, and A. M. J. Koonen, "Discrete multitone modulation for high-speed data transmission over multimode fibers using 850-nm VCSEL," in Proc. OFC/NFOEC 2009, San Diego, CA, Paper OWM2.

[6] R. van Nee and R. Prasad, OFDM for Wireless Multimedia Communications. Boston, MA: Artech House, 2000.

[7] J. A. C. Bingham, "Multicarrier modulation for data transmission: An idea whose time has come," IEEE Commun. Mag., vol. 28, pp. 5-14, 1990.

[8] J. Armstrong, "OFDM for optical communications," IEEE/OSA J. Lightw. Technol., vol. 27, no. 3, pp. 189-204, Feb. 1, 2009.

[9] H. Yang, S. C. J. Lee, E. Tangdiongga, F. Breyer, S. Randel, and A. M. J. Koonen, " $40-\mathrm{Gb} / \mathrm{s}$ transmission over $100 \mathrm{~m}$ graded-index plastic optical fiber based on discrete multitone modulation," in Proc. OFC/ NFOEC 2009, San Diego, CA, Paper PDPD8,.
[10] S. C. J. Lee, "24-Gb/s transmission over $730 \mathrm{~m}$ of multimode fiber by direct modulation of an 850-nm VCSEL using discrete multi-tone modulation," in Proc. OFC 2007, Paper PDP6.

[11] S. C. J. Lee, F. Breyer, S. Randel, R. Gaudino, G. Bosco, A. Bluschke, M. Matthews, P. Rietzsch, R. Steglich, H. P. A. van den Boom, and A. M. J. Koonen, "Discrete multitone modulation for maximizing transmission rate in step-index plastic optical fibres," J. Lightw. Technol., vol. 27, no. 11, pp. 1503-1513, Jun. 1, 2009.

[12] J. M. Cioffi., "A Multicarrier Primer," Jun. 1, 2008 [Online]. Available: http://www-isl.stanford.edu/ cioffi/pdf/multicarrier.pdf

[13] P. S. Chow, J. M. Cioffi, and J. A. C. Bingham, "A practical discrete multitone transceiver loading algorithm for data transmission over spectrally shaped channels," IEEE Trans. Commun., vol. 43, no. 2, pp. 773-775, Feb. 1995.

[14] J. M. Tang and K. A. Shore, "Maximizing the transmission performance of adaptively modulated optical ofdm signals in multimode-fiber links by optimizing analog-to-digital converters," $J$. Lightw. Technol., vol. 25, no. 3, pp. 787-798, Feb. 2007.

[15] S. C. J. Lee, F. Breyer, S. Randel, H. P. A. van den Boom, and A. M. J. Koonen, "High-speed transmission over multimode fiber using discrete multitone modulation [Invited]," J. Opt. Netw., vol. 7, pp. 183-196, 2008.

[16] G. Yabre, "Theoretical investigation on the dispersion of graded-index polymer optical fibers," J. Lightw. Technol., vol. 18, no. 6, pp. 869-877, Jun. 2000.

[17] T. Ishigure, H. Kano, and Y. Koike, "Which is a more serious factor to the bandwidth of GI POF: Differential mode attenuation or mode coupling?," J. Lightw. Technol., vol. 18, no. 7, pp. 959-965, Jul. 2000.

Hejie Yang (S'07) was born in Tianjin, China in 1982. He received the M.Sc. degree in telecommunications from Technical University of Denmark, Denmark, in 2006.

Currently, he is working toward the Ph.D. degree in the area of future home network at COBRA Research Institute, Eindhoven University of Technology, the Netherlands.

Jeffrey Lee (S'06) received the M.Sc. degree in electrical engineering from the Eindhoven University of Technology (TU/e), Eindhoven, the Netherlands, in 2005. He is currently working towards the Ph.D. degree at Siemens AG, Munich, Germany, in collaboration with the TU/e.

In 2003, he started his research with an internship at NTT Photonics Laboratories, Atsugi, Kanagawa, Japan, where he worked on the design and characterization of electro-optical phase modulators. Following that, he conducted his Master's thesis project at Siemens AG in Munich, Germany, dealing with electrical gain control of Erbium-doped fiber amplifiers for long-haul fiber-optic transmission systems. He has authored and co-authored more than 40 refereed papers and conference contributions, including 7 invited papers and a book chapter. His current research is focused on multicarrier modulation techniques such as OFDM and DMT for multimode silica fibers, polymer optical fibers, and optical wireless communications.

Mr. Lee received the Corning Outstanding Student Paper Award at the Conference for Optical Fiber Communication (OFC) in 2009.

Eduward Tangdiongga was born in Makassar, Indonesia, in November 1968. $\mathrm{He}$ received the M.Sc. and Ph.D. degrees from the Eindhoven University of Technology (TU/e), Eindhoven, the Netherlands, in 1994 and 2001, respectively.

In 1994, he joined the COBRA Research Institute. From 2001 to 2006, he participated in the EU FASHION and the Dutch STW research project on ultrahigh-speed optical switch using semiconductor materials. In 2005, he was on a sabbatical leave at Fujitsu Research Labs in Japan working on signal processing using highly nonlinear fibres and quantum-dot semiconductor optical amplifiers. Currently, he is an assistant professor at the TU/e on short-haul communications. Since January 2008, he has been working on optical signal transport and switching for in-home communications in EU FP7 research programs ALPHA, POF-PLUS, and Euro-Fos. He has (co)authored over 100 conference and journal papers. 
Chigo Okonkwo (S'04) was born in the U.K. in 1979. He received the B.Eng. and M.Sc. degrees from University of Essex, Essex, U.K., in 2001 and 2002, respectively.

In 2004, during his Ph.D. research, he joined the Photonic Networks Research Laboratory of University of Essex as a Senior Research Officer working on the UK Technology Strategy Board and EPSRC funded research projects, PROTAGON and HIPNET. Since March 2009, he is working at COBRA Research Institute of Eindhoven University of Technology (TU/e) in the Netherlands as a Researcher. He is contributing to research on high-capacity optical transmission systems for in-home and access networks within EU FP7 research projects ALPHA and POF-PLUS

Henrie van den Boom has been an Assistant Professor at the Electro-Optical Communication Systems group of the COBRA Institute at Eindhoven University of Technology, the Netherlands, since 1984.

He has been involved in national and international research projects on coherent optical communication systems, optical cross-connected networks, broadband communications in Hybrid Fiber Coax networks (ACTS project FLEXIMACS) and Polymer Optical Fiber systems and networks (FP6 project POF-ALL). Presently, he is involved in the access/in-home projects in the European FP7 ICT programme ALPHA, BONE, EuroFOS and POF-PLUS. $\mathrm{He}$ (co-) authored over 120 journal and conference papers.

Florian Breyer (S'06) received his Dipl.-Ing. degree in electrical engineering from Stuttgart University of Technology, Germany, in 2005.

Since then, he has been with the Institute for Communications Engineering, Technische Universität München (TUM) in cooperation with Siemens Corporate Technology, as a research and teaching assistant. His research interests are modeling and equalization schemes for optical transmission systems with Polymer Optical Fiber.
Sebastian Randel (S'02-M'06) received the Dipl.-Ing. and the Dr.-Ing. degrees from the Technical University Berlin, Berlin, Germany, in 2001 and 2005, respectively. His dissertation work dealt with physical layer issues of WDM transmission systems operating at $160 \mathrm{Gbit} / \mathrm{s}$ per wavelength channel.

In 2005, he joined Siemens AG, Corporate Technology, Munich, Germany, as a research scientist. Currently, he is involved in research activities on advanced Ethernet PHY for polymer optical fiber and optical wireless communications. His further research interests include cost-efficient PON architectures, as well as advanced modulation formats for 100-Gbit/s transport networks.

Ton Koonen (F'07) has been a full Professor at the COBRA Institute at Eindhoven University of Technology in the Netherlands, since 2001 and chairman of the Electro-Optical Communication Systems group, embedded in the COBRA institute since 2004.

Prior to that, he spent more than 20 years at Bell Labs in Lucent Technologies as a technical manager of applied research. . Since 2007, he is also an elected member of the IEEE LEOS Board of Governors. Next to his industrial position, he has been a part-time professor at Twente University from 1991 to 2000. His main interests are currently in broadband fibre access and in-building networks. He has initiated and led several European R\&D projects (in FP4: ACTS AC028 TOBASCO, AC349 PRISMA, FP5 IST HARMONICS) on reconfigurable hybrid access and in-home networks, and on optical packet routing in metro networks (FP5 IST STOLAS), as well as several national R\&D projects in these fields. Presently, he is involved in a number of access/in-home projects in the European FP7 ICT programme (ALPHA WP3 leader, BONE WP16 leader; EuroFOS, POF-PLUS), as well as in the Dutch Freeband programme and in the Dutch IOP Generieke Communicatie programme. He (co-)authored over 300 journal and conference papers, and 4 book chapters.

Dr. Koonen is a Bell Labs Fellow and an IEEE Fellow for contributions in high-speed optical transmission systems and broadband optical access systems 